\title{
Hundra år i Diktarhemmet
}

Föredrag vid Svenska litteratursällskapet i Finlands årshögtid den 5 februari 2021

Om Diktarhemmets byggmästare Gotthard Flensborg berättas det, att när han i Waxholm steg ombord på fartyget som skulle segla honom till Sveaborg, fanns han införd i rullorna som tegelslagare, men på Sveaborg landsteg han som fortifikationsbyggmästare. Det är en utomordentlig illustration till det begrepp som kallas bildningsväg. Sällan eller aldrig blir den så konkret som här, där man kan rita in den på ett sjökort.

Jag undrar hur mycket vi har missat, vi som har åkt fram och tillbaka på båtarna mellan Finland och Sverige, genom att inte vara uppmärksamma på de möjligheter och förvandlingar som den här rutten erbjuder. Vad hade vi inte kunnat bli om vi hade förstått att utnyttja den övergång som en sjöresa innebär?

När Helsingforsbåten vek in till Mariehamn den I8 januari 2018 för att plocka upp mig och mitt lilla flyttlass skedde det strax före midnatt, den tidpunkt då de stora förvandlingarna sker. Västra hamnen i Mariehamn har sett alla slags fartyg passera, och min storlek och omfånget på min last klassificerade mig som galeas. Men när jag var framme i Borgå seglade jag in i Diktarhemmet som en fyrmastad bark, med rum för alla mina segel.

Det är underbart med utrymme. När mina små möbler och alla 58 lådor var på plats såg det ut som om man hade slängt en näve ärter över ett loggolv, det rasslade lite och så var det lika tomt. Alldeles ensam klarar man sig inte i en sådan situation, men jag har lyckligtvis en bakgrund där det finns bondgårdar, skeppargårdar och prästgårdar, alla med sal. Diktarhemmet har numera ett inofficiellt vängårdsavtal med Skeppargården Pellas i Lemland, och framför allt tillgång till 
ett nätverk av råd och dåd i Gammelgård i Esbo. Så småningom fick vi ihop möbler och mattor på golvet och gardiner för fönstren och krukväxter i de djupa fönstersmygarna, men det är fortfarande utrymmet som är det allra ljuvligaste här, och det att det är så vackert och har en sådan fin plats i Gamla stan i Borgå.

Jag hade bott i Borgå i många år innan jag flyttade till Mariehamn 20I4. På den tiden i Borgå bodde jag på sjätte våningen i ett betonghus från slutet av i96o-talet med utsikt över Helsingforsvägen, och besökande skönsjälar från Helsingfors brukade säga att jag som konstnär väl inte skulle bo där utan i Gamla stan. Då tittade jag strängt på dem och sa att det funktionella är vackert. Det tycker jag fortfarande, och det var bra att bo på Rådmansgatan, men i Diktarhemmet medger jag att det vackra är snäppet vackrare.

Om Gotthard Flensborg finns det för övrigt en del att berätta. Han kom alltså till Sveaborg, men tubbades över till Borgå som stadsbyggmästare efter Borgå brand I76o då största delen av staden brann ner. I rask takt byggde han rådhuset och tre stora fina stenhus längs ån. Som tack fick han den prestigefyllda tomten strax nedanför domkyrkan. Som stadsbyggmästare var det hans uppgift att propagera för stenhus, och han hade därför inget val: stenhus måste det bli fast det hade varit betydligt billigare att bygga ett trähus. Huset han byggde var en vit elefant som åt upp allt han fick loss, och fast han hade fått tillstånd att hålla krog i bottenvåningen fick han aldrig någon riktig ordning på sin ekonomi. Hans sista bragd består i att han som en av de få lyckades ta sig förbi den redan då mycket noggranna folkbokföringen och försvinna utan spår. Det finns inget respass, det finns ingen anteckning i kyrkboken om att han var utflyttad eller död, inte heller någon fint snickrad minnesdikt som brukade bestås stadens mera bemärkta invånare. Kvar finns bara min förhoppning om att han efter en nattlig båtfärd landsteg i en ny identitet, till ett nytt liv.

Hustru och barn blev kvar i Borgå, och med Flensborgska gården gick det utför. Krogtillståndet drogs in och nya ägare tog över. Efter ett tag blev det lönnkrog med lösa kvinnor och gården fick ett så dåligt rykte att det berättas att familjeflickor inte fick gå ensamma förbi här utan måste eskorteras. Huset var ansenligt förfallet när bokförläggare Holger Schildt med fru bestämde sig för att köpa det. Det var I9I9, strax efter inbördeskriget, och gick billigt, men renoveringsbehovet 
var enormt, och två år senare donerade herrskapet Schildt gården till Finlands svenska författareförening, med stipuleringen att den skulle användas som hedersbostad för en finlandssvensk författare, och att Hjalmar Procopé skulle vara den första invånaren i huset.

Ordförande för författarföreningen vid den här tiden var Arvid Mörne, som bör äras för att han vågade ta emot donationen. Pengar i den storleksklass som upprustningen krävde fanns naturligtvis inte, och det kostade säkert en ansenlig möda att skrapa ihop de behövliga donationerna från lokala företag, främst i Borgå, och från företag och institutioner i Sverige, som vid den här tiden strax efter inbördeskriget omfattade Finland med sympati och generositet. Albert Bonniers förlag, till exempel, bidrog med en rejäl summa. Renoveringen blev utomordentligt lyckad. Bara två år efter donationen kunde man ta Diktarhemmet i bruk.

I åttio år vilade ansvaret för Diktarhemmet på Finlands svenska författareförening innan man år 20or överlät det till Svenska litteratursällskapet. Underbara människor, för övrigt, som säger "Det drabbar ingen fattig" när något måste fixas. De kostade på sig en väldigt vacker ytrenovering innan jag flyttade in, och installerade ett nytt värmesystem. Med författarföreningen fortsätter huset att ha de varmaste relationer: där finns ju alla kolleger och själva rekryteringsbasen, och Diktarhemmet ska framför allt vara ett litteraturens hus.

I hundra år nu har Diktarhemmet varit ett hus som lever och andas litteratur. $\mathrm{Nu}$ ska jag berätta hur en litterär dag i Diktarhemmet kan se ut.

Jag sitter och dricker morgonte i köket längst nere i huset. Då ringer telefonen högst uppe på tredje våningens svindlande höjder. Jag kutar uppför alla trappor och svarar i telefonen precis när den som ringt knäpper av. Jag ringer upp och hälsas av en glad röst som frågar: Gissa vem som kommer på middag? En hel skock, visar det sig. Åh! Den som befann sig fjärran från vimlets yra! Jag inser att jag får lov att skrota mina planer på en promenad över floden in bland träden. Det är sol över backen och över fjärden är himlen hög, men det har jag inget för. Jag måste rusa raka vägen ut och handla och sedan dra mitt lass tillbaka till köket och försöka rusta till Babettes gästabud. Men lugn, bara lugn. Om man håller på tillräckligt länge så blir det hyfsat bra till slut. Mellan verserna ilar jag genom rummen 
och kollar att de är något så när presentabla. Jag susar också genom Gröna rummet, där porträtten av mina föregångare, som jag tänker på som mina sju bröder, hänger. De vägrar att se mig i ögonen och tycks mena att om man håller sig undan fixar någon annan det.

Och nu kommer redan gästerna. Soppan bränns i botten och grönsakerna kokar sönder medan jag tar emot Borgmästaren i Casterbridge, Prästen i Uddarbo, Markurells i Wadköping, Doktor Glas, Fru Catharina Boije och hennes döttrar, Bröderna Karamazov, Anna Karenina, Madame Bovary, Nana och Lolita, Smugglarkungen, Margareta Jönsdotter till Bastö, Kristin Lavransdotter, Jane Eyre, David Copperfield, Oliver Twist, Don Juan och Damen med hunden. Till sist kommer också Godot, som vi har väntat på. Underbara människor allihop. I Diktarhemmet visar sig alla från sin bästa sida, och mellan oss finns det en gammal bekantskap och gemensamma erfarenheter som förenar oss och motsatta ståndpunkter som borgar för livliga samtal. Livet är en fest med sådana vänner, och ingen vill gå hem från festen. Maten var förstås inte allt man kan önska sig, men jag tröstar mig med att ingen dog, och förresten kommer väl ingen till Diktarhemmet bara för matens skull. Hoppas jag i alla fall.

När jag har vinkat av gästerna vid sista bussen är det bara att kavla upp ärmarna och röja av. Rapport från en skurhink ska jag förskona er ifrån. När det äntligen är klart sjunker jag ner vid köksbordet och drar andan. En liten stund är jag helt borta med vinden. Jag sitter där i mina penséer på spaning efter en tid som flytt. Jag tänker på Kökar och mina år i stora världen, jag tänker på min tid som fågel i Sibirien, jag tänker på Hiroshima mon amour, jag tänker på mina öar i Afrikas inre, jag tänker på den afrikanska farmen, där floden flyter förbi. Framför allt önskar jag mig hundra år av ensamhet så att jag äntligen ska få en chans att skriva på min roman.

Och nu talar vi allvar, för jag har kommit in på det som är den stora paradoxen i Diktarhemmet. Om man bor i ett så vackert hus, och har en sådan sal, kommer gästfriheten av sig själv. Naturligtvis vill man ha folk här, visst tar man emot, och visst blir det trevligt. Och som skalden nästan sa, det är roligt att ha trevligt, i själva verket är det roligare att vara intensivt social än att skriva. 
Att skriva kräver ett annat läge, en nedtoning, en frånvändhet, en nedstigning, en segdragen stillsam depression som för många av oss är en del av kreativiten och inte kräver någon diagnos. När man är glad och pratsam skriver man inga böcker, och vi alla som har bott och bor här delar erfarenheten att vi är satta här i huset för att vi skriver böcker men har tilldelats eller snarare antagit en roll som följer med huset och gör det riktigt svårt att komma till.

Därför ekar Diktarhemmet inte bara av animerade samtal och glada skratt utan också av djupa suckar och svåra kval.

Mina kolleger, de sju bröderna, träffar jag i Gröna rummet, som ligger granne med biblioteket. Här har vi i ordningsföljd Hjalmar Procopé, Bertel Gripenberg, Jarl Hemmer, Rolf Lagerborg, Rabbe Enckell, Lars Huldén och Christer Kihlman. De tre sista träffade jag under mina år i Borgå, de andra har jag blivit bekant med genom deras böcker. I biblioteket finns Procopés boksamling, vackra halvfranska band men också en mängd små häftade diktsamlingar innehållande en stor del av den tidens finlandssvenska diktskatt.

Böckerna är vackra och jag tycker mycket om att sitta i biblioteket, trots att jag har blandade känslor för Procopés boksamling. Den fungerar som ett memento mori: det står bara en stavningsreform mellan oss och den stora glömskan. När den tas i bruk blir våra böcker lika mossiga som artonhundratalets litteratur kan verka i dag. I mindre drastisk form är den här utvecklingen i riktning mot det gamla och förlegade redan i gång. Jag talar på ett annat sätt än dagens unga, jag använder en del för dem främmande ord och vändningar. Det jag skriver om ligger inte i deras tid. På motsvarande sätt är vissa saker i de yngre generationernas språk och litteratur främmande för mig. Jag är medveten om att vi har olika erfarenheter och referensramar, jag är tacksam för att jag är så gammal att jag inte behöver ta "hen” i bruk. Jag upplever med andra ord en generationsklyfta som jag aldrig trodde att jag skulle stå inför när jag själv var ung.

Jag kan alltså gott sluta mig till de övriga i Gröna rummet: vi är alla författare som har haft sin tid. Om man accepterar att vi tillhör och skriver våra böcker för den tid vi lever i är det lättare att acceptera att vi i olika grad är på väg ut ur den levande samtidslitteraturen. De litterära omvärderingarna som alltid är på gång både i litteraturvetenskapen och det allmänna medvetandet är inte okända för någon av oss 
i Gröna rummet. Den enda som egentligen har klarat sig helt skottfri är Lars Huldén som gör att vi alla ler vid blotta namnet. Det gick så mödolöst när han skrev, han var så fantastiskt produktiv, han var så tillgänglig, han hittade genast orden, han var ett fenomen. Dessutom hade han Bojen, som var en enorm tillgång för Diktarhemmet och får stå som representant för Diktarhemmets alla kvinnor, mindre kända än sina män, men viktiga garanter för allt liv i huset.

Vissa av oss kommer lättare undan än andra, också de som liksom bara försvinner ur det allmänna medvetandet som Hjalmar Procopé, som slipper bli hånad för sina dramer på klassiska teman, och Rolf Lagerborg, på sin tid en stor dissident, som nu är den minst kända i skaran - inte ett ont ord om honom heller, eller om Christer Kihlman, vår stora kamikazeförfattare, så radikal i sina teman att han fortfarande är en förebild och tillhör vår samtid.

Annat är det med Bertel Gripenberg, ovedersägligen en stor poet men naglad vid inbördeskriget genom sin hatpoesi och senare aktivitet $\mathrm{i}$ Lapporörelsen som ger honom tätpositionen som vår största fascist. Det är för övrigt intressant att han under hela sin karriär var fullständigt gångbar i de bättre kretsarna, sin fascism till trots. I Gröna rummet sitter han i alla fall i snygg vit kostym målad av självaste Edelfelt och säger något som inte är alldeles lätt att tolka om vikten av härstamning och klasstillhörighet i sin tids Svenskfinland.

Gripenberg efterträddes i Diktarhemmet av Jarl Hemmer, i många avseenden Gripenbergs motsats. Där Gripenberg var viss om sin historiska bestämmelse var Hemmer full av tvivel. Där Gripenberg hyllade styrka och beslutsamhet var Hemmer medveten om sin svaghet, labil och kastad från kris till kris. Han omvärderade tidigt sina krigiska dikter i början av inbördeskriget och genomgick perioder av tvivel och självanklagelser innan han samlade sig till romanen En man och hans samvete om fånglägret på Sveaborg. Den kom ut först I93I, men var fortfarande djärv i sin utmaning av den vita sidans sanningar.

Ändå är det Hemmer som kom att bli föremål för en ganska skoningslös omvärdering redan i unga år. Han började bra som gudarnas gunstling, guldlockig och älskad av publiken. Han skrev fint rimmad strålande bra poesi och blev på kort tid en uppburen finlandssvensk skald. Men till hans personliga olycka sammanföll hans tid som författare med modernismens genombrott, som han inte kunde omfatta 
för egen del, så väl som rytmen och rimmen satt i hans egen poesi. Han var ännu ung när tiden och den litterära smaken rusade ifrån honom. Visst var han fortfarande en aktad skald men hyperkänslig som han var var han också medveten om den lilla ringaktning han mötte i de tongivande kretsarna. Vid fyrtio års ålder var har passé i somligas ögon, och allra mest i sina egna ögon.

Det är helt klart att den tidiga modernismen är den finlandssvenska litteraturens stoltaste stund som vi har levt högt på i alla år. Södergran, Södergran, Södergran, Björling, Diktonius, Parland i pluralis, Hagar Olsson och den stora mängden lyriker och prosaister efter dem. Visserligen blev de häcklade i sin början, men acceptansen var relativt snabb och segern blev total. Viktiga personer i kulturlivet omfamnade dem, svenskarna betraktade dem avundsjukt, en hängiven ny läsekrets tog dem till sig, en helt ny värld öppnade sig, en övergång från det stelnade gamla till det levande nya.

Det finns egentligen bara gott att säga om modernismens tidiga genombrott i Finland. Det är först i sen tid vi börjat skymta en bild av modernismen som en segrare som tar allt och plattar till allt som kommer i dess väg. Det hån som drabbade författarna på förlaget Bro, verksamt i Åbo I939-I962, är ett beklämmande exempel. De stod långt från etablissemanget i Helsingfors och var försvarslösa mot angreppen från eliten om de bristande formella färdigheterna, om det lantligt naiva i motivvalet, om traditionalismen och om folksmaken som uppmuntrade dem. I det här fallet fick också läsarna skarpa tillrättavisningar.

På senare år har vi fått ett par studier som visar på en nattsida i modernismens triumftåg. I sin avhandling Realismens röster. Kvinnliga kontorister $i$ mellankrigstidens finlandssvenska litteratur (20I7), har Eva Johansson visat hur en typ av samtidslitteratur utdömdes av tidens kritiker och självdog som genre. Också en författare som Sally Salminen, som hade gjort sig ett namn med Katrina och blivit insläppt på parnassen men ändå inte medlem av den, blev sargad av kritiken. Hur hennes senare böcker bemöttes av kritiken ger Ulrika Gustafsson en grafisk skildring av i sin bok om Sally Salminen, Min ljusa stad - Sally Salminen, livet och litteraturen (2019).

Jarl Hemmer bodde för övrigt i Diktarhemmet då Sally Salminen och hennes danska man Johannes Dührkop firade smekmånad på 
Societetshuset i Borgå. Det var under kriget, och redan första natten bombarderades Borgå centrum med Societetshus och allt. Jarl och Saga Hemmer bjöd vänligt in paret till Diktarhemmet där de bodde några dagar. Talade de någonsin om kritikens avoghet och elitens nedlåtenhet? Diskuterade de modernismens dominerande position? Kanske gick det för nära och var för skamligt att över huvud taget nämna de stroppiga kritikerna.

Som författare i Diktarhemmet hade Hemmer en plats i etablissemanget men i sina egna ögon var han en total outsider. Hans tid i Diktarhemmet började med en tragedi I933 då hans goda vänner Erik Kihlman och Henry Ericsson med fruar körde ner i ån en becksvart novemberkväll efter en glad middag i Diktarhemmet. Alla fyra omkom, och Jarl Hemmer marterades under resten av sitt liv av skuld och samvetskval. Hans förtvivlan och hans kriser finns manifesterade i hans krucifix som hänger i biblioteket, det rum där han sköt sig I944.

En annan av Diktarhemmets författare som råkade i tänderna på en ny tids litteratursyn var Rabbe Enckell, som bodde i Diktarhemmet 1960-I973. Det ironiska är att han kan klassas som modernist, alltså arvtagare till den litterära riktning som en gång hade sopat golvet med sina föregångare och samtida. Plötsligt stod en ny och självsäker ung generation framför honom och utdömde hans poesi för att den var samhällsfrånvänd och irrelevant i dagens värld. Sextiotalisterna, dit jag själv hör, hade däremot fingret på tidens puls och körde fram samhällsengagemang och starka ställningstaganden mot maktmissbruk och missförhållanden orsakade av det borgerliga samhället. De förespråkade uppror och revolt och motstånd mot det förtryck som finns inbyggt i systemet. Den nya dikt som skrevs kom direkt ur studentupproren och motståndet mot Vietnamkriget, som det inte stod ett ord om i Rabbes lyrik. På det sättet blev han ett exempel på det förlegade i den tradition som länge varit ideal i den finlandssvenska litteraturen. Hallonbackspoesi, kallade man den nu.

Hela gänget bakom kulturtidskriften $F B T$, som de gav ut under några år under den andra hälften av sextiotalet, var unga och fattade kanske ännu inte hur hudlöst sårbar en äldre diktare kunde vara. De flesta, med Claes Andersson i spetsen, blev bemärkta personer i kultur och politik, men när det begav sig insåg de troligen inte vilken auktoritetsposition de höll på att tillskansa sig. Rabbe Enckell blev 
något av en symbol för det nattståndna kulturarvet man ville sopa undan. Angreppet kom oväntat för honom, och förbittrade hans år i Diktarhemmet. I litteraturen är verket och personen i hög grad ett och detsamma och det är ohjälpligt att kritik av verket drabbar personen.

Det jag har talat om här, om verksamhet och glädjeämnen och kriser och kval i Diktarhemmet, gäller de första 98 åren. Det nittionionde och nu det hundrade året ser väldigt annorlunda ut. Jag har själv nyss inlett mitt fjärde år här och har upplevt en annan typ av förvandling än den jag nämnde i början av mitt tal. Normalt liv har förvandlats till riskbeteende, och för att rädda vårt liv måste det stå på sparlåga så länge det krävs. Min generations engagemang för frihet och rättigheter har övergått i senare generationers restriktioner och förbud. Som fenomen är det här i högsta grad intressant, försöker jag intala mig. Vi befinner oss mitt inne i ett gigantiskt experiment i pandemihantering som vi aldrig har försökt oss på förut. Allt är med andra ord nytt, och det finns massor av okända faktorer och konsekvenser som mår bra av att synas i sömmarna. Jag tycker därför att det är berättigat att kasta en kritisk blick på det som händer.

Det här ödsliga året när jag har skramlat omkring i Diktarhemmet som en ärta i en plåtburk har jag tänkt mycket på det betänkliga i att våra demokratier genom pandemihanteringen har börjat se väldigt mycket totalitärare ut. Jag säger inte att de har blivit det permanent, men det skadar inte att vara uppmärksam på den här utvecklingen. Det är inte okontroversiellt att staten har tagit sig sådana rättigheter över oss. Det ligger något illavarslande i hur lätt det gick och hur allmän acceptansen är. Och vilka otäcka modeller det nu finns för framtida kriser.

Det här är inte platsen att diskutera pandemihanteringen, men nog att tala om hur det berör kulturlivet. Under hösten när teatrar och konsertsalar, operan, museer och gallerier, auditorier och mötesplatser tilläts hålla öppet, sköttes de rigorösa säkerhetsföreskrifterna till punkt och pricka, och vad jag vet har man inte kunnat spåra några utbrott av smitta till något kulturevenemang. Ändå har i stort sett hela kulturlivet varit nedsläckt sedan den 23 november 2020. Jag ansluter mig till dem som protesterar mot det här. 
Jag hör förstås alla de här tysta invändningarna: inte är kulturlivet nedsläckt, ingen hindrar er att jobba, vi streamar och zoomar så det står härliga till och får mycket uppskattning för det. Vi har aktivitet som aldrig förr. Digitaliseringen har tagit jättekliv framåt. Detta är framtiden! Okej, men se på mej: här står jag, all dressed up and nowhere to go, och vidhåller att kultur är på riktigt, en levande process och ett utbyte mellan levande människor.

Så hälsningen från Diktarhemmet i kväll lyder: öppna biblioteken - under ansvar, med munskydd - öppna teatrar och konsertsalar och auditorier. Öppna gallerier och museer. Låt kulturlivet blomstra. Låt oss få fira Diktarhemmets hundraårsjubileum med levande sammankomster. 